\title{
The effects of a school-based intervention programme on dietary intakes and physical activity among primary-school children in Trinidad and Tobago
}

\author{
Marlon Francis ${ }^{1,2}$, Selby SD Nichols ${ }^{1, *}+$ and Nequesha Dalrymple ${ }^{3}$ \\ 'University of the West Indies, St. Augustine, Trinidad and Tobago: ${ }^{2}$ National School Dietary Services Limited, \\ Trinidad and Tobago: ${ }^{3}$ University of The Southern Caribbean, Maracas, St. Joseph, Trinidad and Tobago
}

Submitted 19 March 2008: Accepted 10 March 2009: First published online 10 February 2010

\begin{abstract}
Objective: Childhood obesity is increasingly being recognized as a major public health problem in the Caribbean. The objective of the present study was to evaluate the effectiveness of a short-term, school-based, multi-component education intervention on improving the knowledge, attitudes and behaviour of primary-school children towards better dietary and activity habits.

Design: The study was a randomized, controlled, school-based nutrition education and physical activity intervention. Participating schools were randomly assigned to the intervention (IVG) and non-intervention (NIVG) groups.

Setting: All primary schools in Sangre Grande, north-east Trinidad.

Subjects: Five hundred and seventy-nine pupils in their sixth year of primaryschool education were enrolled from twelve schools in Sangre Grande, north-east Trinidad.

Results: Approximately $23 \%$ of participants had $\mathrm{BMI} \geq 85$ th percentile of the Centers for Disease Control and Prevention age- and gender-specific cut-off values. In multivariate regression equations controlling for age, gender, BMI and baseline value, intervention was associated with lower intake levels of fried foods, snack foods high in fat, sugar and salt (HFSS) and sodas $(P<0 \cdot 05)$. In similar analyses, intervention was associated with higher knowledge scores $(P<0 \cdot 01)$. Intervention was not significantly associated with physical activity and Children's Eating Attitude Test-26 (ChEAT26) scores after controlling for age, gender, BMI and the relevant baseline values.

Conclusions: The intervention was associated with lower intake levels of fried foods, HFSS foods, sodas and higher knowledge scores independent of age, gender, BMI, ethnicity and the appropriate baseline value. Finally, the intervention was not associated with changes in physical activity behaviours in multivariate analyses.
\end{abstract}

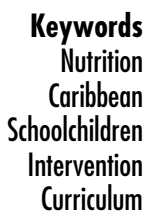

Diseases associated with Westernized lifestyles such as diabetes, CVD, cancers and hypertension are the major causes of illness and death in many countries of the Caribbean $^{(1)}$. This is in stark contrast to the situation a mere five to six decades ago, where infectious diseases coupled with undernutrition were the most pressing concerns facing the health system ${ }^{(2)}$. The solution of these initial health concerns necessitated region-wide public health programmes aimed primarily at disease prevention. Health promotion, education, hygiene and vaccination formed the core of many of these programmes. The alacrity of this epidemiological shift from high levels

$\uparrow$ Correspondence address: c/o Department of Agricultural Economics and Extension, University of the West Indies, Trinidad. of undernutrition and infectious disease to high levels of overnutrition and chronic non-communicable diseases has caught many regional governments by surprise, and few have been able to stem the increasing economic burden of treating these diseases. This overall pattern of increasing levels of chronic non-communicable diseases may reflect the results of deleterious physiological adaptations to the dramatic changes in the environmental milieu that have accompanied economic development ${ }^{(1,3)}$. Most worrying is the fact that the effects of overnutrition are already present in many of the children in the Caribbean. In fact, childhood obesity is rapidly becoming a major issue in the Caribbean ${ }^{(4,5)}$. Consumption patterns among many of the region's children reflect high levels of fat, sugar and salt in the diet, and low 
consumption of traditional foods rich in complex carbohydrates, vegetables and food from plants ${ }^{(6,7)}$. Conservative estimates suggest the economic cost of treating and managing obesity and its co-morbid conditions regionally amount to some one billion US dollars per year ${ }^{(8)}$. As with the initial public health crisis of infectious diseases within the region in the post-colonial era, a major solution to this contemporaneous situation largely depends on creating an enabling environment that fosters the development and inculcation of sustainable health, dietary and lifestyle practices ${ }^{(9,10)}$.

Nutrition knowledge, attitudes and behaviours learned during childhood have the potential to be sustainable over the individual's lifespan and hence contribute to reduced risk of developing chronic diseases ${ }^{(11,12)}$. Evidence to date suggests that school-based curriculum interventions can play an important role in promoting lifelong healthy eating in an environment that is conducive to behavioural change ${ }^{(13)}$. In addition, the results of randomized trials have suggested that such interventions can have sustainable positive impacts on knowledge, attitudes and behaviours ${ }^{(14)}$. Moreover, programmes that included appropriate curriculum, physical education, family involvement and an enabling school food environment appeared to have better success rates ${ }^{(15)}$. In the context of Trinidad and Tobago, the school environment provides excellent opportunities to practise healthy eating, as many of the primary schools have government-sponsored breakfast and lunch programmes. School-based interventions can also serve as entry points for the development or enhancement of policies that can assist in the promotion of healthy schools ${ }^{(16)}$.

Unfortunately, not enough research has been done to identify interventions that can impact positively and address the many facets of the childhood obesity epidemic regionally. One such curriculum-based intervention implemented by the Caribbean Food and Nutrition Institute, 'Project Lifestyle', while successful in achieving behaviour changes, has not been adapted by many governments of the region as it did not address issues of cost, ease of implementation, cultural relevance and adaptability ${ }^{(2)}$. Before any intervention is adopted, it must address these issues. In the present study we evaluated the efficacy of a short-term multicomponent intervention on dietary practices and related behaviours, as well as its acceptability and the ease of implementation and integration in the current curriculum.

\section{Materials and methods}

\section{Population}

Sangre Grande, located in north-east Trinidad, is considered rural. Its prime economic activities are centred on agriculture. Results of the mandatory primary schools' National Assessment Examinations suggest that schools in this region of the country obtain marks in numeracy and literacy that are among the lower percentiles nationally.
The majority of students attending these schools are resident within the region. We reasoned that a schoolbased curriculum intervention that is comprehensible to this group would meet the criteria for comprehensibility for those students whose scores are among higher percentiles. We targeted students in the sixth year of primary school, as they would be easily followed up after the transition to secondary school. The questionnaire was designed at a comprehension level that was one reading grade level lower than that of the targeted population.

\section{Study design and sample}

The study was a randomized controlled intervention among twelve schools in the district of Sangre Grande which met the criterion for the inclusion of having more than fifteen children in the sixth year. One school was randomly selected from this group, using the SPSS for Windows statistical software package version $11 \cdot 0 \cdot 1$ (SPSS Inc., Chicago, IL, USA), for pre-testing of the level of comprehension of the original questionnaire. Following this, modifications were made to ensure adequate comprehension of the items. This school took no further part in the study. Of the eleven remaining schools, five were randomly assigned to the intervention group (IVG) and six to the non-intervention group (NIVG) using a table of random numbers. A total of 579 students in their sixth year of primary-school education were recruited and enrolled in the study. All students in the sixth year at each participating school were afforded the opportunity to participate in the study. We estimated that $50 \%$ of participants in the control group would have dietary intakes of fruit and vegetables that would be below the recommended levels. To detect a $30 \%$ reduction with the intervention at $95 \%$ significance level and a power of $90 \%$, a minimal sample size of 223 participants in each of the IVG and NIVG groups was estimated ${ }^{(17)}$. Approval for the study was granted by the Ministry of Education, University of the West Indies, and school principals and parents of participants. Figure 1 shows the distribution of participants through the study.

\section{Measurements}

\section{Dietary intakes}

Dietary pattern was assessed by a modified Block FFQ designed to gain information on consumption patterns of the following foods: fruits, vegetables, snacks high in fats, sugar and salt (HFSS), fried foods and sodas. The dietary intake section of the questionnaire consisted of a list of foods usually consumed at snack times, as well as at main meals. Blank spaces were left to record foods consumed that were not contained in the list. Participants were required to indicate the frequency and amounts of foods from the indexed food groups consumed over the last week. They were also required to indicate whether it was consumed within the last $24 \mathrm{~h}$. To assist in the accuracy of 


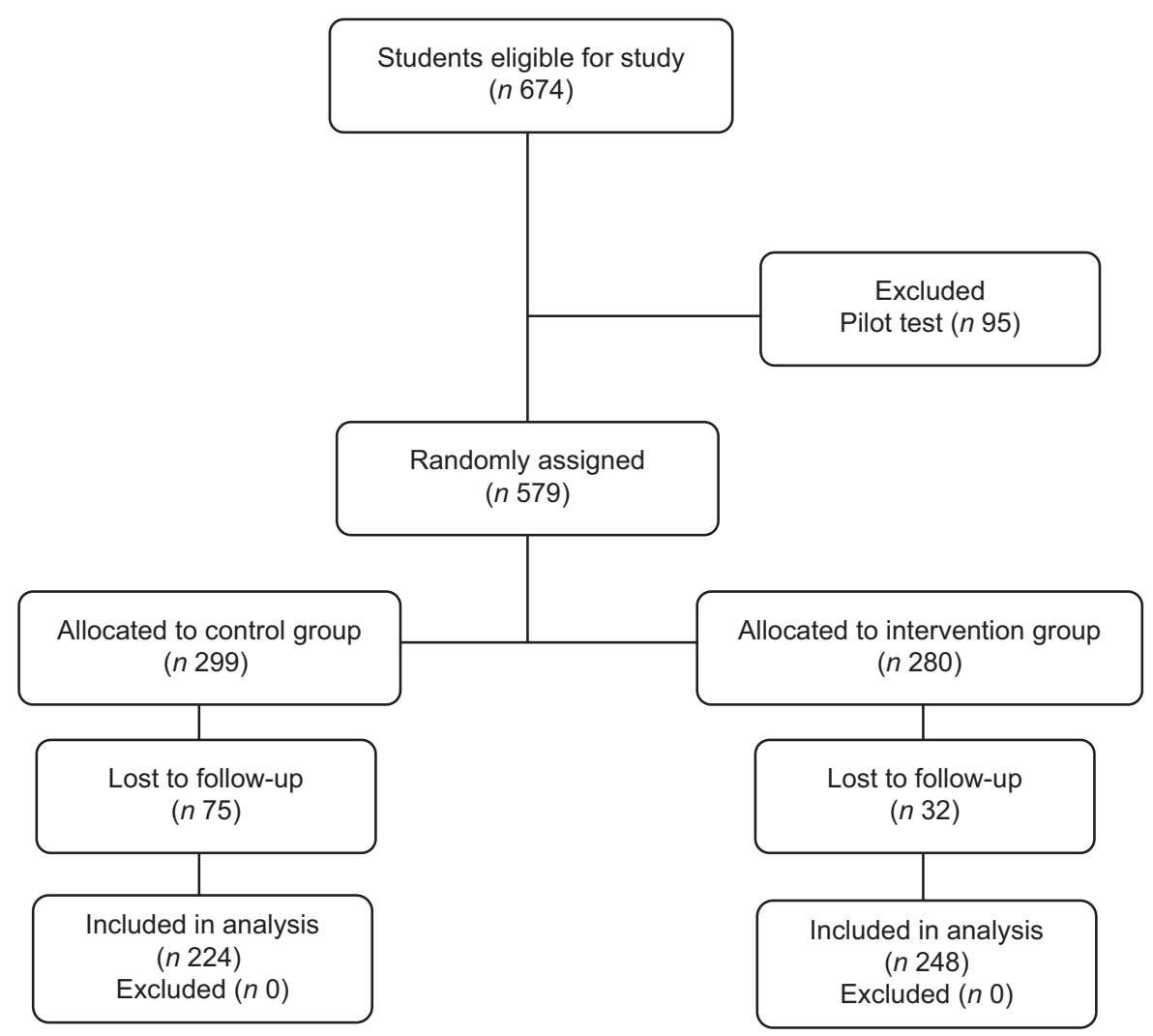

Fig 1 Distribution of participants through the study

recall, the questionnaire was structured on the typical school day. In addition, participants were presented with standard servings of foods and snacks typically consumed, by having on display pictures and actual standard serving sizes of cooked and raw vegetables, beverages, juices and fruits. The average daily serving for each food group was calculated by dividing the total servings of the food group by seven. The food displays were in typical household measures such as cups and spoons, to which standard serving sizes were assigned.

\section{Physical activity}

Participants were questioned on their various types of physical activity for the $7 \mathrm{~d}$ preceding participation in the study. The questionnaire followed the normal structure of a school day to assist the participant in recalling. Physical activity both in and out of school was classified into the following categories: low-intensity activity (e.g. reading a book, sitting in class) and moderate- to high-intensity activity (walking, jogging, playing with friends, playing sports). Students also filled out an open-ended question on the average number of hours spent watching television each day of the week preceding participation in the study. This was used to classify persons into two television viewing categories: category 1 (those viewing television for $\geq 2 \mathrm{~h}$ daily) and category 2 (those viewing television for $<2 \mathrm{~h}$ daily).

\section{Curriculum components}

The curriculum consisted of lessons on nutrition and physical activity based on Bloom's mastery learning model. The modules incorporated three domains of educational activities: cognitive, affective and psychomotor. The content of the curriculum engaged the students in the learning process with activities and experiences geared towards broadening their interest. Knowledge on the six food groups, sources of nutrients and types of food was evaluated using a basic nutrition test. In activity one, students were required to insert the correct responses in spaces left blank in a paragraph. Activity two required the matching of foods and nutrients, and activity three required students to identify the foods that were high in sugar, salt and fats. Students also took part in activities where they worked in teams to solve comprehension, vocabulary and mathematics questions based on nutritionally related issues. The physical activity component was assessed by the student's ability to follow and instruct their classmates on the different types of exercises and their effects on the body. The physical activity lesson was aimed at increasing energy expenditure both at school and at home. The lesson was taught in class and on the playing field. Simple exercises that lasted for $10 \mathrm{~min}$ were used to demonstrate endurance, strength and flexibility activities. These student-led exercise activities were carried out on the school's playing field 
with the accompaniment of the local music genre, 'Soca'. All activities took into consideration requirements of the normal school curriculum. That is, the modules contained activities that would allow students to fulfil their curriculum mandate of numeracy and literacy. Each module was followed by an assessment that evaluated concept design. Mastery required that $75 \%$ of participants would score $75 \%$ or greater on the assessment of each module. All persons involved in the intervention were trained to administer questionnaires, measure height and weight accurately, prepare serving portions, assess knowledge and understand and apply activities that were part of the intervention. Weekly meetings were held with all persons involved in the implementation of the intervention to solve any problems that may have arisen and to ensure quality of measurements and continued standardization of instructions.

\section{Procedure}

The study was conducted from 6 September 2006 to 30 April 2007. The detailed curriculum was developed, validated and approved at the University of the West Indies with input from primary-school curriculum officers of the Ministry of Education. Prior to implementation of the curriculum, the intervention questionnaire was developed and pilot-tested on children ( $n$ 95) of similar ages from a randomly selected school in the area under study. All necessary adjustments were made to the instruments and it was retested one month later. Teachers who volunteered underwent extensive training geared at standardization of measurement, and delivery and evaluation of the content of the various modules. Baseline data for all participating schools were collected during the month of October 2006. The intervention was conducted in the IVG schools for one month. On the day of study, each participant had anthropometry measured by health professionals trained specifically for the study. Weight was measured to the nearest $0 \cdot 1 \mathrm{~kg}$ with an electronic weighing scale (model 770; Seca Corp., Hanover, MD, USA), while height was measured to the nearest millimetre with a portable stadiometer (Seca Corp.) with participants standing on a horizontal surface with their bodies fully extended and their heads in the Frankfurt plane $^{(18)}$. The averages of two readings each for weight and height were used in subsequent analyses. BMI was calculated as weight in kilograms divided by the square of height in metres $\left(\mathrm{kg} / \mathrm{m}^{2}\right)$. BMI was categorized using the Centers for Disease Control and Prevention (CDC) ageand gender- specific cut-off values for overweight (85th percentile $\leq$ BMI $>95$ th percentile) and obesity (BMI $\geq$ 95th percentile) ${ }^{(19)}$. All measurements were done with the students in school uniform with shoes removed and pocket contents emptied.

In addition, participants completed the Children's Eating Attitude Test-26 (ChEAT26). This is a twenty-six-item measure that yields a single index of disordered eating attitudes and could provide a measure of participant's feelings and perceptions towards eating (e.g. 'I do not eat when I am hungry'). Participants were required to rate how each question applied to them by selecting 'always', 'very often', 'often', 'sometimes', 'rarely' or 'never'. These were then scored as recommended ${ }^{(20)}$. Trained personnel were available to assist students where there might have been difficulties in understanding issues on the questionnaire.

The intervention questionnaire was re-administered in all participating schools three months following the end of the intervention. We also asked staff and teachers of the intervention schools and classes to rate several aspects of the intervention. The items were as follows: (i) Quality of course material; (ii) Clarity of delivery of course material; (iii) Content of course; (iv) Quality of activities (including quizzes); (v) Reported student impression of the course material; and (vi) Your overall opinion of the study unit. Teachers were asked to rate these six questions using the following scale: 'very good' $=5$, 'good' $=4$, 'average' $=3$, 'bad' $=2$, 'very bad' $=1$, no response $=0$. Two more questions followed: (vii) These modules overtly disrupted class schedules; and (viii) Nutrition education should be incorporated into the school curriculum. The following categories were given as possible responses: 'strongly agree' $=4$, 'agree' $=3$, 'disagree' $=2$, 'strongly disagree' $=$ 1 , 'undecided' $=0$. The final questions, (ix) 'What were the positive points of this exercise?' and ( $\mathrm{x}$ ) 'What could be improved?', were open-ended. Figure 2 summarizes the overall study implementation.

\section{Statistical analysis}

The SPSS for Windows statistical software package version $11 \cdot 0 \cdot 1$ (SPSS Inc., 2001) was used to analyse the data. To assess differences between the intervention and nonintervention groups as well as between baseline and postintervention, the $\chi^{2}$ test was performed for categorical data. For continuous data, the $t$ test was used for normally distributed variables and the Mann-Whitney test was used when variables were not normally distributed. We then conducted multivariate linear and logistic regression analyses to assess the effect of the intervention. For each analysis, the change in the variable from baseline to postintervention was entered as the dependent variable. Age, $\mathrm{BMI}$, gender and the baseline value of the change variable were entered as independent variables.

\section{Results}

Five hundred and seventy-nine (280 in the IVG and 299 in the NIVG) students were enrolled in the study. Table 1 shows the characteristics of participants. Participants in the NIVG were significantly older, taller and had higher mean BMI than their counterparts in the IVG. In addition, a significantly higher proportion of them had $\mathrm{BMI} \geq 85$ th percentile of the CDC age- and gender-specific reference. 
(PHASE 1)

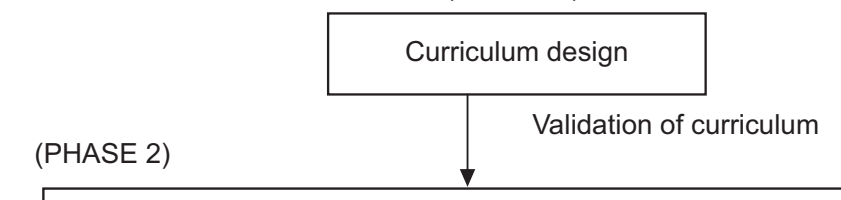

Nutrition education intervention questionnaire development

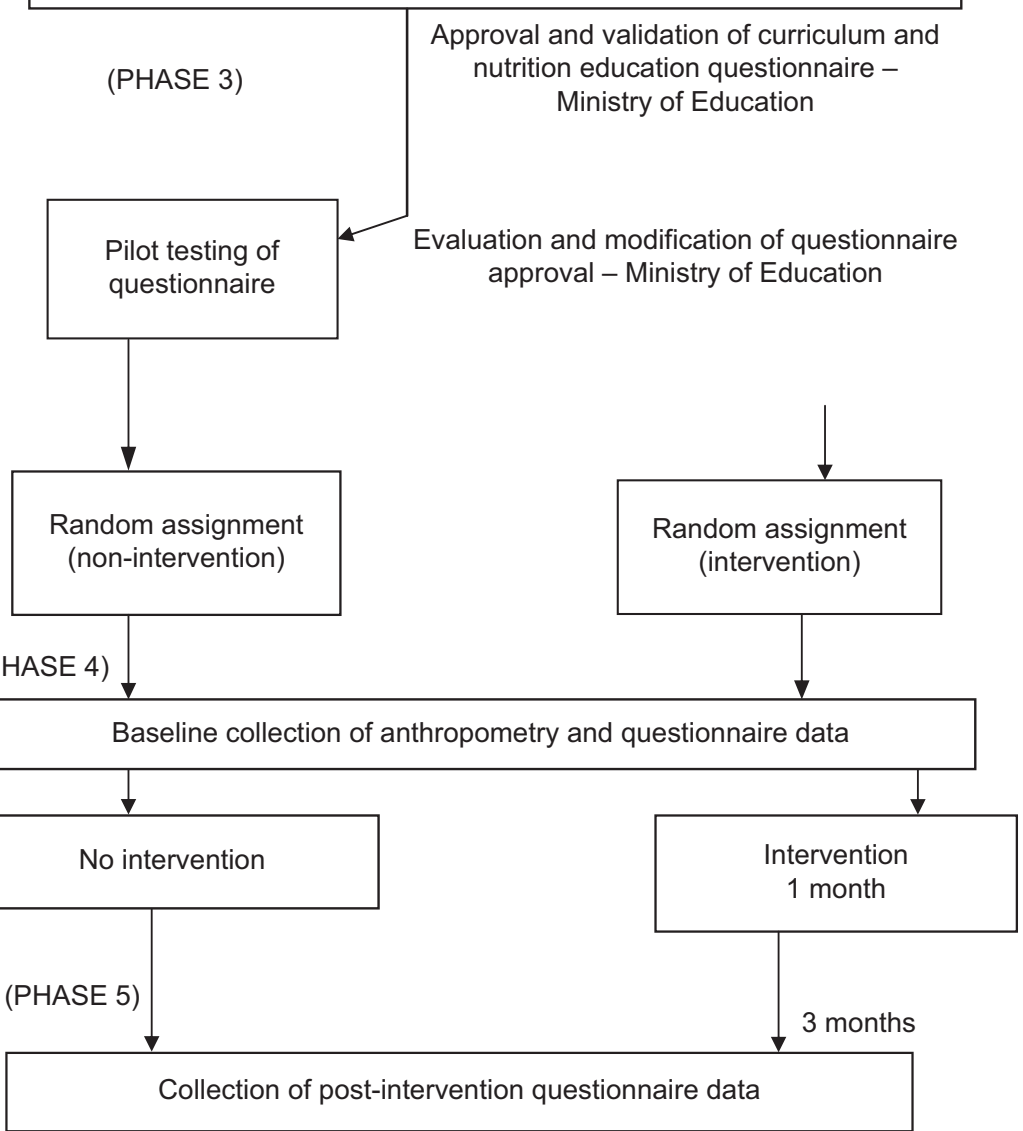

Fig. 2 Summary of overall study implementation

Approximately $23 \%$ of participants had BMI $\geq 85$ th percentile of the CDC age- and gender-specific reference. There were significantly higher percentages of Christians and Hindus in the NIVG and IVG, respectively. Table 2 shows knowledge, attitudes to eating and intakes of fruit and vegetables at baseline and post-intervention by group status. At baseline, a significantly higher proportion of persons in the NIVG than the IVG reported fruit and vegetable consumption levels $\geq 2$ servings/d. There were no significant differences in the proportion of persons reporting fruit and vegetable consumption levels $\geq 2$ servings/d between the IVG and the NIVG post-intervention. The intervention resulted in a significant change in the proportion of persons within the IVG reporting fruit consumption levels $\geq 2$ servings/d. Compared with the persons in the IVG, there was a reduction in the proportion of persons in the NIVG consuming $\geq 2$ servings of vegetables daily; however, this was not statistically significant $(P=0 \cdot 06)$. Notwithstanding, there was a significantly greater absolute change in the proportion of persons reporting vegetable consumption within the past $24 \mathrm{~h}$ at the post-intervention assessment in the IVG than the NIVG. Persons in the IVG had on average significantly larger changes in their knowledge scores than participants in the NIVG. Participants in the IVG had significantly lower ChEAT26 scores than their counterparts in the NIVG from baseline to the post-intervention assessment. However, both groups experienced a similar reduction in their ChEAT26 scores from baseline to the post-intervention assessment.

Table 3 shows the pattern of consumption of fried foods, HFSS foods and sodas at baseline and post-intervention by group status. Participants in the IVG reported significantly higher mean intakes of sodas than those in 
Table 1 Characteristics of participants by group: pupils in sixth year of primary-school education enrolled from schools in Sangre Grande, north-east Trinidad, 2006-7

\begin{tabular}{|c|c|c|c|c|c|}
\hline \multirow[b]{2}{*}{ Variable } & \multicolumn{2}{|c|}{ IVG (n 248) } & \multicolumn{2}{|c|}{ NIVG $(n$ 224) } & \multirow[b]{2}{*}{$P$ value } \\
\hline & Males & SD & Males & SD & \\
\hline Age (years) & $10 \cdot 2$ & $1 \cdot 0$ & $10 \cdot 6$ & $1 \cdot 2$ & $<0.01$ \\
\hline Weight $(\mathrm{kg})$ & $37 \cdot 4$ & $10 \cdot 4$ & $45 \cdot 0$ & $18 \cdot 4$ & $<0.01$ \\
\hline Height $(\mathrm{cm})$ & $144 \cdot 6$ & $7 \cdot 7$ & $146 \cdot 2$ & $8 \cdot 6$ & $<0.05$ \\
\hline \multirow[t]{2}{*}{ BMI $\left(\mathrm{kg} / \mathrm{m}^{2}\right)$} & $17 \cdot 7$ & $3 \cdot 9$ & $20 \cdot 9$ & 8.5 & $<0.01$ \\
\hline & \multicolumn{2}{|c|}{$\%$} & \multicolumn{2}{|c|}{$\%$} & \\
\hline \multicolumn{6}{|l|}{ Gender } \\
\hline Males & \multicolumn{2}{|c|}{54} & \multicolumn{2}{|c|}{50} & NS \\
\hline Females & \multicolumn{2}{|c|}{46} & \multicolumn{2}{|c|}{50} & \\
\hline \multicolumn{6}{|l|}{ BMI group } \\
\hline $\mathrm{BMI}<85$ th percentile & \multicolumn{2}{|c|}{$74 \cdot 4$} & \multicolumn{2}{|c|}{$80 \cdot 7$} & $<0.05$ \\
\hline 85th percentile $\leq \mathrm{BMI}<95$ th percentile & \multicolumn{2}{|c|}{$2 \cdot 1$} & \multicolumn{2}{|c|}{$6 \cdot 4$} & \\
\hline $\mathrm{BMI} \geq 95$ th percentile & \multicolumn{2}{|c|}{$23 \cdot 6$} & \multicolumn{2}{|c|}{$12 \cdot 9$} & \\
\hline \multicolumn{6}{|l|}{ Religion } \\
\hline Christian & \multicolumn{2}{|c|}{53.9} & \multicolumn{2}{|c|}{$78 \cdot 7$} & $<0.01$ \\
\hline Hindu & \multicolumn{2}{|c|}{$33 \cdot 7$} & \multicolumn{2}{|c|}{$11 \cdot 7$} & \\
\hline Muslim & \multicolumn{2}{|c|}{$7 \cdot 4$} & \multicolumn{2}{|c|}{$5 \cdot 0$} & \\
\hline Other & \multicolumn{2}{|c|}{$5 \cdot 0$} & \multicolumn{2}{|c|}{$4 \cdot 6$} & \\
\hline
\end{tabular}

IVG, intervention group; NIVG, non-intervention group; NS, non-significant at the $5 \%$ level.

Table 2 Knowledge, attitudes to eating and intakes of fruit and vegetables at baseline (B) and post-intervention (P) by group status: pupils in sixth year of primary-school education enrolled from schools in Sangre Grande, north-east Trinidad, 2006-7

\begin{tabular}{|c|c|c|c|c|}
\hline & Variable & IVG $(n 248)$ & NIVG $(n$ 224) & $P$ value \\
\hline B & Fruit intake $\geq 2$ servings/d (\%) & $49 \cdot 0$ & $61 \cdot 2$ & $<0.01$ \\
\hline \multirow[t]{3}{*}{$\mathrm{P}$} & Fruit intake $\geq 2$ servings/d (\%) & $73 \cdot 5$ & $68 \cdot 7$ & NS \\
\hline & Change & +25 & $+5 \cdot 1$ & \\
\hline & $P$ value & $<0.01$ & NS & \\
\hline \multirow{4}{*}{$\mathrm{P}$} & Fruit eaten in past $24 \mathrm{~h}(\%)$ & $90 \cdot 6$ & $88 \cdot 4$ & NS \\
\hline & Fruit intake in past $24 \mathrm{~h}(\%)$ & $90 \cdot 6$ & $85 \cdot 6$ & NS \\
\hline & Change & 0 & $-2 \cdot 8$ & \\
\hline & $P$ value & NS & NS & \\
\hline B & Vegetable intake $\geq 2$ servings/d (\%) & 33.9 & $47 \cdot 0$ & $<0.01$ \\
\hline \multirow[t]{3}{*}{$P$} & Vegetable intake $\geq 2$ servings/d (\%) & $32 \cdot 1$ & $38 \cdot 2$ & NS \\
\hline & Change & $-1 \cdot 8$ & $-8 \cdot 8$ & \\
\hline & $P$ value & NS & NS & \\
\hline B & Vegetables eaten in past $24 \mathrm{~h}(\%)$ & $60 \cdot 3$ & $74 \cdot 1$ & $<0.01$ \\
\hline \multirow[t]{3}{*}{$P$} & Vegetables eaten in past $24 \mathrm{~h}(\%)$ & $71 \cdot 4$ & $78 \cdot 8$ & NS \\
\hline & Change & $+8 \cdot 9$ & $+4 \cdot 7$ & \\
\hline & $P$ value & $<0.01$ & NS & \\
\hline B & Percentage knowledge score, mean (SD) & $46 \cdot 0(19 \cdot 4)$ & $41 \cdot 3(23 \cdot 1)$ & $<0.01$ \\
\hline \multirow[t]{3}{*}{$P$} & Percentage knowledge score, mean (SD) & $73.5(18.8)$ & $49 \cdot 5(19 \cdot 8)$ & $<0.01$ \\
\hline & Change & $+27 \cdot 5$ & $+8 \cdot 2$ & \\
\hline & $P$ value & $<0.01$ & $<0.01$ & \\
\hline B & ChEAT26 score, mean (SD) & $12 \cdot 1(9 \cdot 5)$ & $13 \cdot 8(9 \cdot 7)$ & NS \\
\hline \multirow[t]{3}{*}{$\mathrm{P}$} & ChEAT26 score, mean (SD) & $9 \cdot 7(7 \cdot 9)$ & $11 \cdot 4(8 \cdot 8)$ & $<0.05$ \\
\hline & Change & $-2 \cdot 4$ & $-2 \cdot 4$ & \\
\hline & $P$ value & $<0.01$ & $<0.01$ & \\
\hline
\end{tabular}

IVG, intervention group; NIVG, non-intervention group; ChEAT26, Children's Eating Attitude Test-26; NS, non-significant at the $5 \%$ level.

the NIVG at baseline. While there was no significant difference in mean weekly soda consumption between the groups post-intervention, participants in the NIVG doubled their mean weekly intake of soda over the period of the study $(P<0 \cdot 01)$. There was a significant decline in the proportion of persons consuming soda in the $24 \mathrm{~h}$ preceding the post-intervention data collection in the IVG. On the other hand, there was a significant increase in the proportion of persons consuming soda in the $24 \mathrm{~h}$ preceding the post-intervention data collection in the NIVG.
Average reported daily servings of fried foods were significantly lower in the IVG than the NIVG. In addition, there was a significant decline in reported fried food intake in the IVG at the post-intervention assessment compared with baseline.

Finally, there was a significant increase $(+12 \cdot 0 \%$; $P<0 \cdot 01)$ and decline $(-26 \cdot 0 \% ; P<0 \cdot 01)$ in the proportion of persons reporting participation in regular moderate- to- high-intensity activity at school at least 3 times per week in the IVG and NIVG, respectively (Table 4). Also, 
Table 3 Pattern of consumption of soda, fried foods and HFSS foods at baseline $(B)$ and post-intervention $(P)$ by group status: pupils in sixth year of primary-school education enrolled from schools in Sangre Grande, north-east Trinidad, 2006-7

\begin{tabular}{|c|c|c|c|c|}
\hline & Variable & IVG (n 248) & NIVG $(n$ 224) & $P$ value \\
\hline B & Soda intake 8 oz servings/week, mean (SD) & $4.6(3.9)$ & $3 \cdot 4(3 \cdot 6)$ & $<0.05$ \\
\hline \multirow[t]{3}{*}{$\mathrm{P}$} & Soda intake 8 oz servings/week, mean (SD) & $5 \cdot 6(4 \cdot 1)$ & $7 \cdot 7(5 \cdot 8)$ & NS \\
\hline & Change & +0.9 & $+4 \cdot 5$ & \\
\hline & $P$ value & NS & $<0.01$ & \\
\hline B & Soda intake in past $24 \mathrm{~h} \mathrm{( \% )}$ & $67 \cdot 4$ & $53 \cdot 2$ & $<0.01$ \\
\hline \multirow[t]{3}{*}{$\mathrm{P}$} & Soda intake in past $24 \mathrm{~h}(\%)$ & $51 \cdot 3$ & $62 \cdot 8$ & $<0.01$ \\
\hline & Change & $-16 \cdot 1$ & $+9 \cdot 6$ & \\
\hline & $P$ value & $<0.01$ & $<0.05$ & \\
\hline B & Fried food servings/d, mean (SD) & $3 \cdot 0(3 \cdot 1)$ & $2.4(2.5)$ & $0 \cdot 12$ \\
\hline \multirow[t]{3}{*}{$P$} & Fried food servings/d, mean (SD) & $1 \cdot 7(2 \cdot 1)$ & $2 \cdot 2(2 \cdot 5)$ & 0.04 \\
\hline & Change & $-1 \cdot 3$ & -0.2 & \\
\hline & $P$ value & $<0.01$ & NS & \\
\hline B & Fried food eaten in past $24 \mathrm{~h}(\%)$ & $85 \cdot 0$ & $74 \cdot 4$ & $<0.01$ \\
\hline \multirow[t]{3}{*}{$P$} & Fried food eaten in past $24 \mathrm{~h}(\%)$ & $67 \cdot 8$ & $75 \cdot 2$ & NS \\
\hline & Change & $-17 \cdot 0$ & 0.05 & \\
\hline & $P$ value & $<0.001$ & NS & \\
\hline B & HFSS foods $502 \mathrm{~kJ} / \mathrm{d}$, mean (SD) & $4 \cdot 6(4 \cdot 4)$ & $4.5(5 \cdot 2)$ & NS \\
\hline \multirow[t]{3}{*}{$P$} & HFSS foods $502 \mathrm{~kJ} / \mathrm{d}$, mean (SD) & $3 \cdot 2(4 \cdot 1)$ & $4 \cdot 2(5 \cdot 5)$ & NS \\
\hline & Change & $-1 \cdot 4$ & 0.2 & \\
\hline & $P$ value & $<0.01$ & NS & \\
\hline B & HFSS foods eaten in past $24 \mathrm{~h}(\%)$ & $85 \cdot 0$ & $74 \cdot 4$ & NS \\
\hline \multirow[t]{3}{*}{$P$} & HFSS foods eaten in past $24 \mathrm{~h}(\%)$ & $67 \cdot 8$ & 74.5 & NS \\
\hline & Change & $-11 \cdot 0$ & +0.12 & \\
\hline & $P$ value & $<0.01$ & NS & \\
\hline
\end{tabular}

IVG, intervention group; NIVG, non-intervention group; HFSS foods, snack foods that are high in fats, sugar and salt; NS, non-significant at the $5 \%$ level.

Table 4 Physical activity pattern at baseline $(B)$ and post-intervention $(P)$ by group status: pupils in sixth year of primary-school education enrolled from schools in Sangre Grande, north-east Trinidad, 2006-7

\begin{tabular}{|c|c|c|c|c|}
\hline & Variable & IVG (n 248) & NIVG ( $n$ 224) & $P$ value \\
\hline B & Moderate- to high-intensity physical activity $\geq 1 \mathrm{~h} /$ week (\%) & $51 \cdot 2$ & $76 \cdot 8$ & $<0.01$ \\
\hline \multirow[t]{3}{*}{$P$} & Moderate- to high-intensity physical activity $\geq 1 \mathrm{~h} /$ week (\%) & $64 \cdot 4$ & $51 \cdot 2$ & $<0.01$ \\
\hline & Change & $+12 \cdot 0$ & $-25 \cdot 6$ & \\
\hline & $P$ value & $<0.01$ & $<0.01$ & \\
\hline B & Vigorous activity in past $24 \mathrm{~h}(\%)$ & $51 \cdot 3$ & $53 \cdot 2$ & NS \\
\hline \multirow[t]{3}{*}{$P$} & Vigorous activity in past $24 \mathrm{~h}(\%)$ & $67 \cdot 4$ & $62 \cdot 8$ & NS \\
\hline & Change & $+16 \cdot 1$ & $+9 \cdot 6$ & \\
\hline & $P$ value & $<0.01$ & $<0.05$ & \\
\hline B & Frequency of low-level activity/week, mean (SD) & $3 \cdot 0(3 \cdot 1)$ & $2 \cdot 4(2 \cdot 5)$ & NS \\
\hline \multirow[t]{3}{*}{$P$} & Frequency of low-level activity/week, mean (SD) & $1 \cdot 7(2 \cdot 1)$ & $2 \cdot 2(2 \cdot 5)$ & $<0.05$ \\
\hline & Change & $-1 \cdot 3$ & $-0 \cdot 2$ & \\
\hline & $P$ value & $<0.01$ & NS & \\
\hline B & Low-level activity in past $24 \mathrm{~h}(\%)$ & $85 \cdot 0$ & $74 \cdot 4$ & $<0.01$ \\
\hline \multirow[t]{3}{*}{$P$} & Low-level activity in past $24 \mathrm{~h}(\%)$ & $67 \cdot 8$ & $75 \cdot 2$ & NS \\
\hline & Change & $-17 \cdot 0$ & +0.05 & \\
\hline & $P$ value & $<0.01$ & NS & \\
\hline B & Television viewing $\geq 2 \mathrm{~h} / \mathrm{d}(\%)$ & $44 \cdot 9$ & $36 \cdot 0$ & NS \\
\hline \multirow[t]{3}{*}{$P$} & Television viewing $\geq 2 \mathrm{~h} / \mathrm{d}(\%)$ & $44 \cdot 2$ & $58 \cdot 5$ & $<0.01$ \\
\hline & Change & $-0 \cdot 7$ & +23.5 & \\
\hline & $P$ value & NS & $<0.01$ & \\
\hline
\end{tabular}

IVG, intervention group; NIVG, non-intervention group; NS, non-significant at the $5 \%$ level.

there was a significant increase in the proportion of participants reporting television viewing for $\geq 2 \mathrm{~h}$ daily relative to baseline in the NIVG only $(+23.0 \% ; P<0.01)$.

Table 5 shows the results of multivariate analyses. In multivariate regression equations controlling for age, gender, BMI and baseline value, intervention was significantly associated with lower intake levels of fried foods, sodas, HFSS foods and higher knowledge scores. Intervention was not significantly associated with fruit and vegetable intakes, physical activity and ChEAT26 scores after controlling for age, gender, BMI and the relevant baseline values. Further adjusting for ethnicity did not change these findings.

\section{Teachers' and principals' rating of the intervention}

On the issues of quality of course material, clarity of delivery of course material, course content, quality of 
Table 5 Regression analyses for post-intervention dietary intakes and physical activity controlling for the effects of group status, gender, age, BMI and baseline: pupils in sixth year of primary-school education enrolled from schools in Sangre Grande, north-east Trinidad, 2006-7

\begin{tabular}{|c|c|c|c|c|c|}
\hline & \multicolumn{5}{|c|}{ Post-intervention } \\
\hline & Soda & Fried foods & HFSS foods & Vegetables & Fruit \\
\hline \multirow{9}{*}{$\begin{array}{l}\text { Constant } \\
\text { Status } \\
\text { Gender } \\
\text { Age } \\
\text { BMI } \\
\text { Baseline } \\
\text { Adjusted } R^{2}\end{array}$} & 0.43 & 0.36 & $5 \cdot 70$ & $9 \cdot 00$ & $11 \cdot 48$ \\
\hline & $-0 \cdot 17^{\star}$ & $-0 \cdot 13^{\star}$ & $-8 \cdot 80^{*}$ & $-1 \cdot 50$ & 3.08 \\
\hline & $0 \cdot 14^{*}$ & 0.001 & 0.79 & $-2 \cdot 9^{\star}$ & $-3 \cdot 39$ \\
\hline & -0.03 & -0.03 & $1 \cdot 70$ & 0.48 & 3.09 \\
\hline & 0.0006 & -0.0002 & -0.23 & $-0 \cdot 71$ & $-3 \cdot 70$ \\
\hline & $-0 \cdot 01^{\star}$ & -0.001 & $0 \cdot 36^{\star *}$ & $0 \cdot 22^{\star \star}$ & $0 \cdot 24^{\star *}$ \\
\hline & $3 \cdot 6$ & 0.4 & $12 \cdot 0$ & $6 \cdot 7$ & $5 \cdot 7$ \\
\hline & \multicolumn{5}{|c|}{ Post-intervention } \\
\hline & $\begin{array}{l}\text { Moderate- to high-intensity } \\
\text { physical activity }\end{array}$ & $\begin{array}{c}\text { Low-intensity physical } \\
\text { activity }\end{array}$ & $\begin{array}{c}\text { Television } \\
\text { viewing }\end{array}$ & Knowledge & ChEAT26 \\
\hline Constant & $4 \cdot 60^{\star \star}$ & $3 \cdot 40^{\star \star}$ & 0.45 & $14 \cdot 72$ & $9 \cdot 07$ \\
\hline Status & -0.05 & -0.51 & $-0 \cdot 24$ & $6 \cdot 50^{\star *}$ & $-1 \cdot 06$ \\
\hline Gender & 0.34 & -0.44 & $0 \cdot 38^{*}$ & $-1 \cdot 07^{\star}$ & -0.29 \\
\hline Age & -0.08 & 0.09 & 0.07 & $-0.57^{\star}$ & $-6 \cdot 17$ \\
\hline BMI & -0.01 & $-0.05^{\star}$ & 0.004 & $0 \cdot 09^{*}$ & -0.03 \\
\hline Baseline & $0 \cdot 12^{*}$ & 0.04 & $0 \cdot 28^{\star *}$ & $0 \cdot 30^{\star *}$ & 0.27 \\
\hline Adjusted $R^{2}$ & $1 \cdot 0$ & $2 \cdot 0$ & $0 \cdot 4$ & $40 \cdot 7$ & $9 \cdot 0$ \\
\hline
\end{tabular}

HFSS foods, snack foods that are high in fats, sugar and salt; ChEAT26, Children's Eating Attitude Test 26. ${ }^{\star} P<0.05,{ }^{* *} P<0.01$.

activities, reported student impression of the course material and overall opinion of the study unit, teachers and principals in the intervention schools gave ratings of very good. They were of the opinion that the intervention did not affect the regular scheduling of classes. They also felt that nutrition education should be a part of the school curriculum. Some felt that it was time to reintroduce the school nurse, or someone trained to deal with the many nutrition issues that arise, in the primary school setting.

\section{Discussion}

In the present study, the effectiveness of a short-term, school-based, multi-component education intervention on improving the knowledge, attitudes and behaviour of primary-school children towards better dietary and activity habits was evaluated. The results suggest that the intervention resulted in significantly lower reported intakes of sodas, fried foods and HFSs foods after controlling for age, gender, BMI and baseline intakes of these foods. The intervention had no impact on fruit and vegetable intakes after controlling for age, gender, BMI and baseline intakes of these foods. Such variations in findings by food group have been demonstrated in other studies $^{(21-23)}$. These findings suggest that the mechanisms influencing changes in the consumption of these foods might be different ${ }^{(24-26)}$. They might also suggest the need to take into consideration the environmental context in which food consumption occurs in designing effective interventions ${ }^{(27-29)}$. Most of the participants in the current study were enrolled in the National School-feeding Programme. This programme attempts to provide participants with one-third of their daily dietary requirements. It is not uncommon to find vegetables remaining after consumption of these meals. While such programmes are well poised to make healthy choices of fruit and vegetables a regular part of the built environment at school, the home environment in which healthy eating behaviours are fostered is crucial to sustaining the appropriate behaviour changes ${ }^{(30-32)}$.

Our intervention was quite successful in improving the children's knowledge and awareness on issues related to nutrition and physical activity. This is consistent with the findings of other studies and suggests that our intervention may be applicable to our entire primary-school population ${ }^{(21,33,34)}$. The fact that schools in the study region are in the lower percentiles of the standard school assessment examinations conducted by the Ministry of Education of Trinidad and Tobago, suggests that this intervention can significantly improve knowledge among students in the better performing percentiles. The limited contact hours with participants suggests that even short exposure in a well-designed and culturally relevant school-based intervention can result in significant increases in knowledge and awareness among children in a cost-effective manner ${ }^{(34)}$. Our post-intervention evaluation of the curriculum with teachers and principals of all the intervention schools suggests that the intervention was successful and they were eager to include it as part of the primary-school curriculum. They were quite impressed with the ease of implementation and the minimal disruption to the already packed curriculum. Students enjoyed the myriad of interactive activities that were part of the curriculum. Students also had the opportunity to contribute to the learning process by sharing their views on particular topics. Group activities as well as individual 
assignments were carried out during the sessions and students were encouraged to share with the class their reflections of the lessons learnt. A reward system was used to keep students motivated throughout the sessions. All students were presented with tokens for participating in the exercise while top students were rewarded with a special prize. Mastery was set at $75 \%$ for the evaluation of classroom activities. Overall, 65\% of the students were able to achieve mastery of the modules. This suggests that the mechanism underlying behaviour changes in this population goes beyond issues associated with knowledge and awareness.

Our results suggest that the intervention had no significant impact on physical activity level when age, BMI, gender and baseline level of physical activity were taken into consideration. This is consistent with the findings of other studies, which suggest an overall failure of schooland curriculum-based intervention aimed at sustainable increases in physical activity in childhood ${ }^{(35)}$. Clearly, there is an urgent need to evaluate different types of interventions in our population in order to identify those that are effective in increasing participation in physical activity among our children. In this regard, interventions should contain components that are family- and primarybased as these types of intervention have had moderate success rates $^{(36)}$.

Although the findings suggest that the intervention effected behavioural changes, the true impact of the intervention in question can only be gauged by long-term follow-up. The study was conducted in one area of the country that may not be representative of the general population. Moreover, intakes and physical activity were self-reported and therefore subject to recall biases. Given these potential sources of error the results should be interpreted with caution.

\section{Conclusion}

The intervention was associated with lower intake levels of fried foods, HFSS foods and soda after controlling for age, gender, BMI and the appropriate baseline value. It also resulted in greater knowledge and awareness on issues related to nutrition and physical activity. Finally, the intervention was associated with changes in physical activity behaviours in multivariate analyses.

\section{Acknowledgements}

The study was self-funded. The authors are knowledgeable of and are in compliance with the journal's conflict of interest policy. We therefore declare no conflict of interest. S.S.D.N. was responsible for the design of the investigation, statistical analyses and the writing of the many drafts and final manuscript. M.F. was responsible for the recruitment, implementation of field operations and the writing and revision of the final manuscript. N.D. participated in the coordination of data management, writing of the many draft manuscripts and writing and revising the final manuscript. We extend special thanks to all the principals, teachers and participants of the study, without whom the intervention would not have been a success. In addition, we thank the management and staff of the National Schools Dietary Services Ltd, especially Ms Ingrid Herrera, Mrs Avyann Patterson and Mr Raphael Calderia whose efforts in the field assisted the smooth execution of the intervention.

\section{References}

1. Pan American Health Organization \& the Caribbean Community Secretariat (2006) Report of the Caribbean Commission on Health and Development. Jamaica: Ian Randle Publishers.

2. Sinha DP (1992) Project lifestyle: developing positive health lifestyles for schoolchildren in Antigua. J Sch Health 62, 449-453.

3. James WP (2005) The policy challenge of coexisting undernutrition and nutrition-related chronic diseases. Matern Child Nutr 1, 197-203.

4. Gaskin PS, Broome H, Alert C et al. (2008) Misperceptions, inactivity and maternal factors may drive obesity among Barbadian adolescents. Public Health Nutr 11, 41-48.

5. Jackson M, Samms-Vaughan M \& Ashley D (2002) Nutritional status of 11-12-year-old Jamaican children: coexistence of under- and overnutrition in early adolescence. Public Health Nutr 5, 281-288.

6. Luke A, Cooper RS, Prewitt TE et al. (2001) Nutritional consequences of the African diaspora. Annu Rev Nutr 21, 47-71.

7. Popkin BM (2006) Global nutrition dynamics: the world is shifting rapidly toward a diet linked with noncommunicable diseases. Am J Clin Nutr 84, 289-298.

8. Henry FJ (2006) New strategies needed to fight obesity in the Caribbean. http://www.paho.org/English/CFNI/cfnicaj37No104.pdf (accessed February 2007).

9. Rosenkranz RR \& Dzewaltowski DA (2008) Model of the home food environment pertaining to childhood obesity. Nutr Rev 66, 123-140.

10. Papas MA, Alberg AJ, Ewing R et al. (2007) The built environment and obesity. Epidemiol Rev 29, 129-143.

11. Tercyak KP \& Tyc VL (2006) Opportunities and challenges in the prevention and control of cancer and other chronic diseases: children's diet and nutrition and weight and physical activity. J Pediatr Psychol 31, 750-763.

12. Adamson AJ \& Mathers JC (2004) Effecting dietary change. Proc Nutr Soc 63, 537-547.

13. Campbell KJ \& Hesketh KD (2007) Strategies which aim to positively impact on weight, physical activity, diet and sedentary behaviours in children from zero to five years. A systematic review of the literature. Obes Rev $\mathbf{8}$, 327-338.

14. Linksvan Sluijs EM, McMinn AM \& Griffin SJ (2007) Effectiveness of interventions to promote physical activity in children and adolescents: systematic review of controlled trials. BMJ 335, 703.

15. Summerbell CD, Waters E, Edmunds LD et al. (2005) Interventions for preventing obesity in children. Cochrane Database Syst Rev issue 3, CD001871.

16. Bundy D (2005) School health and nutrition: policy and programs. Food Nutr Bull 26, Suppl. 2, S186-S192. 
17. Schulz KF \& Grimes DA (2005) Sample size calculations in randomised trials: mandatory and mystical. Lancet 365, 1348-1353.

18. Lohman T, Roche A \& Martorell R (editors) (1988) Anthropometric Standardization Reference Manual. Champaign, IL: Human Kinetics Books.

19. Kuczmarski RJ, Ogden CL, Grummer-Strawn LM et al. (2000) CDC growth charts: United States. Adv Data 314, 1-27.

20. Maloney MJ, McGuire JB \& Daniels SR (1988) Reliability testing of a children's version of the Eating Attitude Test. J Am Acad Child Adolesc Psychiatry 27, 541-543.

21. Anderson AS, Porteous LE, Foster E et al. (2005) The impact of a school-based nutrition education intervention on dietary intake and cognitive and attitudinal variables relating to fruits and vegetables. Public Health Nutr 8, 650-656.

22. Eriksen K, Haraldsdóttir J, Pederson R et al. (2003) Effect of a fruit and vegetable subscription in Danish schools. Public Health Nutr 6, 57-63.

23. Mangunkusumo RT, Brug J, de Koning HJ et al. (2007) School-based internet-tailored fruit and vegetable education combined with brief counselling increases children's awareness of intake levels. Public Health Nutr 10, 273-279.

24. Nanney MS, Haire-Joshu D, Elliott M et al. (2005) Evaluating changeability to improve fruit and vegetable intake among school aged children. Nutr J4, 34.

25. Bere E, Veierød MB, Bjelland M et al. (2006) Outcome and process evaluation of a Norwegian school-randomized fruit and vegetable intervention: Fruits and Vegetables Make the Marks (FVMM). Health Educ Res 21, 258-267.

26. Resnicow K, Davis RE, Zhang G et al. (2008) Tailoring a fruit and vegetable intervention on novel motivational constructs: results of a randomized study. Ann Behav Med 35, 159-169.

27. te Velde SJ, Brug J, Wind M et al. (2008) Effects of a comprehensive fruit- and vegetable-promoting school-based intervention in three European countries: the Pro Children Study. Br J Nutr 99, 893-903.

28. Neumark-Sztainer D, Wall M, Perry C et al. (2003) Correlates of fruit and vegetable intake among adolescents. Findings from Project EAT. Prev Med 37, 198-208.

29. Pérez-Lizaur AB, Kaufer-Horwitz M \& Plazas M (2008) Environmental and personal correlates of fruit and vegetable consumption in low income, urban Mexican children. J Hum Nutr Diet 21, 63-71.

30. Nelson M, Lowes K \& Hwang V; members of the Nutrition Group, School Meals Review Panel, Department for Education and Skills. (2007) The contribution of school meals to food consumption and nutrient intakes of young people aged 4-18 years in England. Public Health Nutr 10, 652-662.

31. Aranceta Bartrina J \& Pérez-Rodrigo C (2006) Resources for a healthy diet: school meals. Br J Nutr 96, Suppl. 1, S78-S81.

32. Schor EL; American Academy of Pediatrics Task Force on the Family (2003) Family pediatrics: report of the Task Force on the Family. Pediatrics 111, 1541-1571.

33. Spiegel SA \& Foulk D (2006) Reducing overweight through a multidisciplinary school-based intervention. Obesity (Silver Spring) 14, 88-96.

34. Subba Rao GM, Rao DR, Venkaiah K et al. (2006) Evaluation of the Food and Agriculture Organization's global school-based nutrition education initiative, Feeding Minds, Fighting Hunger (FMFH), in schools of Hyderabad, India. Public Health Nutr 9, 991-995.

35. Salmon J, Booth ML, Phongsavan P et al. (2007) Promoting physical activity participation among children and adolescents. Epidemiol Rev 29, 144-159.

36. van Sluijs EM, McMinn AM \& Griffin SJ (2008) Effectiveness of interventions to promote physical activity in children and adolescents: systematic review of controlled trials. $\mathrm{BrJ}$ Sports Med 42, 653-657. 